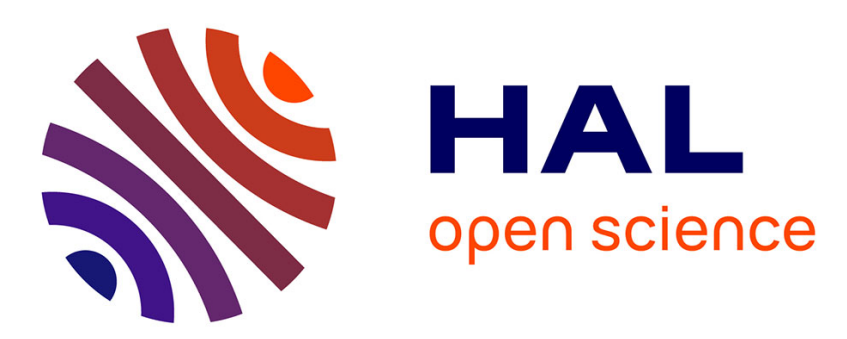

\title{
About the fatigue endurance of unidirectional flax-epoxy composite laminates
}

Thomas Jeannin, Xavier Gabrion, Emmanuel Ramasso, Vincent Placet

\section{To cite this version:}

Thomas Jeannin, Xavier Gabrion, Emmanuel Ramasso, Vincent Placet. About the fatigue endurance of unidirectional flax-epoxy composite laminates. Composites Part B: Engineering, 2019, 165, pp.690 - 701. hal-02131265

\section{HAL Id: hal-02131265 https://hal.science/hal-02131265}

Submitted on 16 May 2019

HAL is a multi-disciplinary open access archive for the deposit and dissemination of scientific research documents, whether they are published or not. The documents may come from teaching and research institutions in France or abroad, or from public or private research centers.
L'archive ouverte pluridisciplinaire HAL, est destinée au dépôt et à la diffusion de documents scientifiques de niveau recherche, publiés ou non, émanant des établissements d'enseignement et de recherche français ou étrangers, des laboratoires publics ou privés. 


\title{
About the fatigue endurance of unidirectional flax-epoxy composite
}

\section{laminates}

\author{
Thomas Jeannin*, Xavier Gabrion, Emmanuel Ramasso, Vincent Placet \\ Univ. Bourgogne Franche-Comté, FEMTO-ST Institute, UFC/CNRS/ENSMM/UTBM, Department of Applied Mechanics,
} F-25000 Besançon.

* Corresponding author: Email: Thomas.jeannin@femto-st.fr

tel: +33(0)38166 67 28-fax: +33(0)38166 6700

\begin{abstract}
Even if the knowledge on the fatigue behaviour of plant fibre composites has increased steadily in the last few years, some issues still remain open at the present time. Such is the case, for instance, of the high-cycle fatigue strength. Actually, most of the fatigue studies available in the open literature to date are limited to a maximum of 1-2 million cycles. All available stress-life plots exhibit linear trends with constant slope and does not reveal any fatigue limit for these given cycle numbers. So, this paper proposes to investigate the High-Cycle Fatigue behaviour of a flax-epoxy laminated composite. The effect of loading frequency is firstly evaluated on the LowCycle Fatigue behaviour using a multi-instrumented analysis including infrared thermography and acoustic emission. Results show that high frequency could be a suitable method to shorten the fatigue tests and study the High Cycle Fatigue behaviour of this type of composite material. Based on this result, high-frequency $(30 \mathrm{~Hz})$ is used to investigate the behaviour of the flax-epoxy composite on a range of $10^{6}-10^{8}$ cycles. Results show that fatigue damage continues to evolve and the maximum stress continues to decrease as a function of increasing number of cycles, following a power-law trend. This result suggests that, if a fatigue limit does exist for unidirectional flax-epoxy composite laminates, it is so low that it cannot observed in tests up to $10^{8}$ cycles. It is also recommended to take it into consideration when designing plant fibre composite structures.
\end{abstract}

Keywords: A. Polymer-Matrix Composites, B. Mechanical properties, B. Fatigue, D. Mechanical testing

\section{INTRODUCTION}

Fatigue of Plant Fibre Composites (PFCs) has been studied in the last few years [1-15], and most of the available results are critically reviewed in a recent paper [16]. It emphasizes that most of the results are collected on flaxepoxy composites. This strong focus on flax can be explained by its excellent specific mechanical properties as well as by the good technology readiness of the processes related to the manufacturing of fabrics and thus by their availability on the market. Results show that these composite materials exhibit good fatigue performance which is considered comparable to those measured on composites reinforced with glass fibres. Generally, the stress-life (S-N) data follow a linear trend of constant slope. Experimental results show that some of the specimens tested at the lower stress levels survive the maximum number of cycles pre-determined for the test (1-2 million). Based on this result, it is sometimes suggested that a fatigue limit or endurance limit (i.e. a maximum stress at which material can sustain unlimited number of cycles) exists [16]. But, a natural fatigue limit has never been determined experimentally. This suggests that if a fatigue limit does exist, it cannot be 
observed in tests limited to 2 million cycles. So, this paper proposes to investigate the high-cycle fatigue behaviour of a flax-epoxy laminated composite. Indeed, high cycle fatigue is a major criterion for the design in many application sectors, in particular in transportation (by sea, land and air), as well as in energy sector (for the production of wind turbine blades as an example [17]), where mass saving is often a motivation for the substitution of glass fibres by plant fibres. These structures are also subject to a high cycle fatigue. So, the reliable determination of the fatigue endurance of PFCs when they are subjected to a high number of cycles is an important issue for PFCs, as for all organic matrix composites. It is in particular of paramount importance to assess if they have a fatigue limit or if they exhibit a continuously decreasing stress-life response. This is the main objective of this paper.

Determining the fatigue limit of composite materials is a challenging issue. To plot the $\mathrm{S}-\mathrm{N}$ curve, several longlasting tests on similar specimens with different levels of stress must be carried out. As a consequence, considerable time is needed. Time and cost constraints generally hinder the use conventional fatigue testing in the high cycle and very high cycle ranges. The number of cycles is generally selected based on a compromise between the requirements of the application and practical limitations of the test program [18]. Different approaches have been envisioned and proposed, so far, for organic matrix composites, to accelerate the fatigue tests, to minimize the amount of costly and time-consuming experiments with low loads and high number of cycles or to estimate rapidly the fatigue strength using time-saving methods instead of more expensive and laborious Wohler's method. Only few of them have been tested and applied on biobased composites.

Carvelli et al. [18] proposed to use the quasi-static damage threshold to estimate the fatigue limit of textile and short (glass and carbon) fibre reinforced composites. Actually, they observed a good relation between the fatigue life limit and the quasi-static damage threshold and they considered that this later provides rough estimation for the design strains to use under fatigue strength requirements. The weak point of this approach is that the fatigue limit has to be determined beforehand to validate the relation between the quasi-static damage and the fatigue limit is only valid for the considered material.

Other approaches generally consist in keeping a cyclic loading path but with accelerating the fatigue tests by increasing the loading amplitude and/or frequency. Among these approaches, the Lehr's method [19] consists in cyclic loading the material with gradually increasing the amplitude. This method, was first created for metal testing. It relies mainly on the observation that fatigue failure is a consequence of local plastic strains which start to appear after exceeding fatigue strength in individual grains of metal before exceeding yield strain of a whole specimen. This process of failure is accompanied with sudden increase of dissipated energy, temperature and extension. The principle of the method is to record these three parameters under conditions of cyclic loading which gradually increases in amplitude. By plotting these parameters as a function of maximum stress and based on the analysis of these curves, it is possible to determine the fatigue strength. This method was also implemented for polymeric materials. It allowed for determination of the fatigue properties of polyamide filled with mineral tuff filler, composites based on polyhydroxybutyrate filled with natural fibres [20] and biodegradable composites with short flax fibres tested in tension-tension [20].

In the same vein, it is also possible to accelerate and shorten the fatigue tests by increasing the loading frequency. However, this is generally considered as not relevant for organic matrix composites due the material self-heating. For this reason, standards generally stipulate a frequency range from 2 to $10 \mathrm{~Hz}$. Test frequency generally exerts a considerable influence on fatigue processes in polymeric materials [21-23]. For organic matrix composites, the influence of frequency is particularly influential in materials containing off-axis layers due to creep-fatigue interaction. Actually, these materials are matrix dependent and, under cyclic loading, complex and eventually antagonist mechanisms (creep, damage, selh-heating...) can simultaneously occur. For PFCs, both the fibres and the matrix are polymeric materials, so the question can also be raised for unidirectional stacking sequences.

El Sawi et al. [7] proposed to exploit this self-heating behaviour to determine the fatigue limit of flax-epoxy composite using a thermographic criterion and more exactly by measuring the temperature of the external surface of the specimen during the application of cyclic loading. This approach, originally developed for metallic alloys [24], and sometimes called self-heating tests was previously exploited successfully for carbon fibre reinforced polymer composites [25, 26]. It consists in applying successive sets of a given number of cycles for increasing stress levels. For each stress level, the temperature variation is recorded and the steady-state temperature can be determined. Beyond a given limit, it can be observed that the steady state temperature starts to increase significantly. This change is correlated with the state where the fatigue limit is exceeded. The main advantage of this technique is that only few coupons and few hours are required to determine the high cycle fatigue strength with a good accuracy. But, it is also worth noting that the relationship between the dissipated 
heat, the intrinsic energy dissipation and the number of cycles to failure is directly dependent on the nature of the constituents, the lays-up and the size of the coupons. These relationships are not easy to predict using theoretical approach for composite materials meaning that the experimental curve giving the steady-state temperature vs. maximum stress magnitude needs to be constructed whenever one these parameters changes. So the advantage and the time saved using this approach can be debated.

Based on this review of literature, in this paper, the chosen approach was to determine the High-Cycle Fatigue (HCF) life and to shorten the fatigue tests by increasing the loading frequency. The study is focused on a composite reinforced with unidirectional flax fibres.

The first part of the paper investigates the influence of the frequency increase, from 5 to $30 \mathrm{~Hz}$, on the lowcycle fatigue life and damage. To the best author's knowledge, even if literature is well-documented for glass and carbon fibre composites, only few data on the influence of loading frequency on the fatigue behaviour are available for PFCs. Osti de Moares et al. [27] showed on a coir fibre reinforced polypropylene composite that higher loading frequencies promote reduction in fatigue life. This was obtained for a composite reinforced by short fibres. So, it seems crucial to investigate the influence of the loading frequency on the fatigue behaviour of PFCs, in particular for continuous unidirectional fibres.

The second part of the paper is dedicated to the determination of the HCF.

Throughout this paper, we will consider, as it is generally done in the composite literature, that the mechanical fatigue is sub-divided into three ranges: Low Cycle Fatigue (LCF) up to $10^{6}$ cycles to failure; high cycle fatigue (HCF) between $10^{6}$ and $10^{8}$ cycles to failure and very high cycle fatigue (VHCF) over $10^{8}$ cycles to failure [28]. This study is thus focused on the determination of the HCF strength (HCFS) and is also restricted to the case of tension-tension fatigue with a constant applied load ratio (R) of 0.1 .

Two in-situ non-destructive techniques are used in order to detail the fatigue damage scenario: namely, acoustic emission (AE) and infrared (IR) thermography. These techniques have become recognized non-destructive techniques, commonly used to detect, locate and discriminate defects in traditional composite materials [29-33] as well as PFCs [5, 34, 35]. AE are transient elastic waves produced by the sudden internal stress redistribution of the materials caused by the changes within the structure. For polymer-composite materials, these changes are mainly due to crack initiation and growth, crack opening and closure, fibre breakage and fibre-matrix debonding. AE is also the name of the non-destructive technique developed to detect and record these transients. The use of AE during fatigue tests is particularly challenging due to the massive data to be processed as well as to a high $\mathrm{AE}$ events rate that can lead to continuous signals (instead of discrete transients) [36]. A specific methodology and the tools previously developed in FEMTO-ST were used [30] to overcome these difficulties and successfully analysed and exploit the AE data collected during the fatigue tests.

\section{MATERIAL AND METHODS}

\subsection{Specimen preparation}

\subsubsection{Composite material}

Unidirectional flax-epoxy composite plates were fabricated by thermo-compression of the Flaxpreg T-UD material provided by LINEO ${ }^{\circledR}$. It is a range of pre-impregnated material based on an epoxy resin system and a unidirectional flax fibres reinforcement. The flax fabric has an areal weight of $110 \mathrm{~g} / \mathrm{m}^{2}$. The resin that is used is the Huntsman XB3515® and the hardener is the Aradur5021®. The fibre fraction in the prepreg material is approximately $50 \%$ in weight.

\subsubsection{Composite fabrication}

8 plates $(300 \mathrm{~mm} \times 200 \mathrm{~mm} \times 1 \mathrm{~mm}$ ) were fabricated using a thermo-compression machine (AGILA Presse $100 \mathrm{KN}$ ). These plates consist in 8 elementary unidirectional plies. The layers are compressed in an aluminium mould coated with Teflon to prevent resin from sticking to the mould. The composite material is cured for one hour at a temperature of $120^{\circ} \mathrm{C}$. A pressure equal to 3 bars is applied for a period of $1 \mathrm{~h}$ after the temperature of the sample has reached $60^{\circ} \mathrm{C}$. The small gap between the lower and the upper part of the mould allows excess 
air and resin to escape. The resulting average fibre volume fraction of approximately $61 \pm 2 \%$. This volumetric composition was determined following the procedure described in $[4,37]$. A value of $1.47 \mathrm{~g} . \mathrm{cm}^{-3} \mathrm{was}$ considered for the fibre specific gravity, as recommended by Le Gall et al. [38].

\subsubsection{Sample preparation}

Two types of rectangular specimen were cut in the plates using a Trotec Speed300® laser device in the fibre direction.

- Specimens of $240 \mathrm{~mm}$ in length and $15 \mathrm{~mm}$ in width were prepared for tensile monotonic and fatigue testing. These dimensions are in agreement with the ASTM D3039 recommendations. After surface preparation (sanding then cleaning with acetone), tabs made with the same composite materials (40 $\mathrm{mm}$ in length, $15 \mathrm{~mm}$ in width and $1 \mathrm{~mm}$ in thickness) were bonded to the test specimens used a Loctite Super Glue 3 Gel adhesive.

- Smaller specimens were cut for Dynamic Mechanical Analysis (DMA) tests. Their length and width were equal to 50 and $4 \mathrm{~mm}$, respectively.

After fabrication and cutting, samples were stored in a climatic chamber at $23^{\circ} \mathrm{C}$ and $50 \% \mathrm{RH}$ during at least 20 days before mechanical testing.

\subsection{Mechanical testing}

\subsubsection{Monotonic tensile tests}

The tensile properties were determined using an Instron Eletropuls E10000 machine equipped with a $10 \mathrm{kN}$ load sensor (Fig. 1). The axial strain was measured using a clip-on extensometer, with a gauge length of 50 $\mathrm{mm}$. The tensile stress was computed by dividing the applied load by the initial cross-section of the specimen. To evaluate the influence of the loading rate on the monotonic behaviour, samples were subjected to a displacement control; with five different moving crosshead speeds, 0.01, 2, 10, 100 and $4000 \mathrm{~mm}^{\mathrm{min}} \mathrm{m}^{-1}$ respectively. Tests were carried out up to failure. For the determination of the Young's modulus, considering that the materials has a nonlinear relationship between stress and strain that can be roughly assimilated to a bilinear behaviour, two apparent moduli were determined using linear regression respectively between $0.01 \%$ and $0.15 \%$ of strain $\left(\mathrm{E}_{L}^{m 1}\right)$ and between $0.4 \%$ and strain at failure $\left(\mathrm{E}_{L}^{m 2}\right)$. The tangent modulus was also expressed as a function of the axial strain. 3 specimens were tested for each testing speed. Results are presented in terms of average and standard deviation values.

The transverse properties were measured by three-point bending tests performed on a Metravib DMA +300 , in accordance with the ASTM D790. The dimensions of the samples were $60 \mathrm{~mm} \times 10 \mathrm{~mm} \times 1 \mathrm{~mm}$. A cross-head speed of $1 \mathrm{~mm} / \mathrm{min}$ and a span length of $40 \mathrm{~mm}$ were applied. 


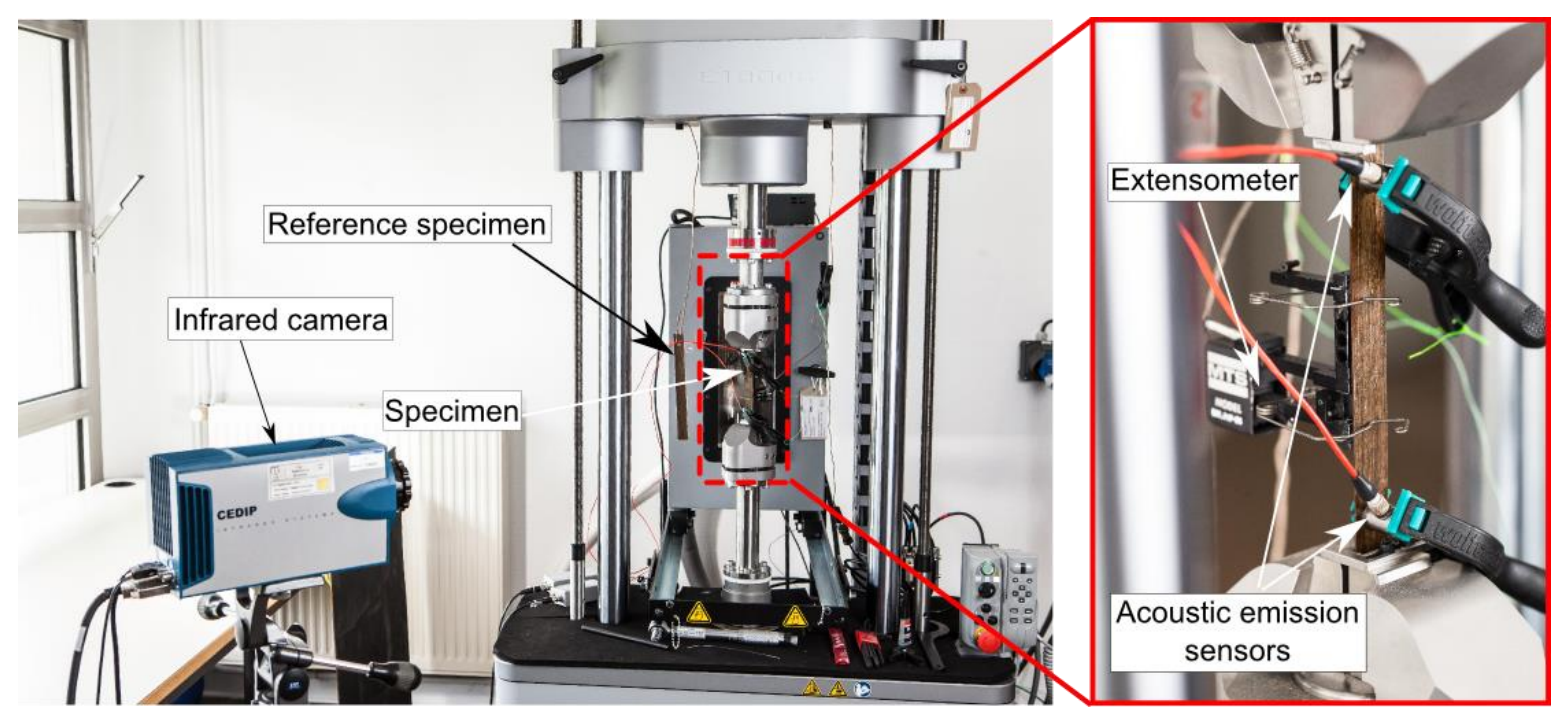

Figure 1: Experimental set-up for fatigue tests with in situ and real-time damage characterization.

\subsubsection{Tensile-tensile fatigue tests}

The tensile-tensile fatigue tests were performed under a sinusoidal waveform loading at two different loading frequencies, 5 and $30 \mathrm{~Hz}$, using a load amplitude control mode, and a ratio between minimum and maximum stress $(\mathrm{R})$ of 0.1 . The experimental configuration (loading machine, specimen shape and preparation) was similar to monotonic tensile tests. Fatigue tests were performed in the fibre direction. Six levels of maximum stress were applied. The levels were 90, 80, 72.5, 65, 57.5 and $50 \%$ of the mean quasi-static tensile failure stress $\sigma_{\mathbf{L}}$ (itself measured at $2 \mathrm{~mm} \cdot \mathrm{min}^{-1}$ ). At least three replicates were tested at each stress level. Tests were stopped at failure.

At $30 \mathrm{~Hz}, 5$ other loading levels were tested: 61, 47.5, 45, 40 and 35\% of the mean quasi-static tensile failure stress. For the test with a loading level of $35 \%$, just one specimen was tested.

Peak-to-peak and average amplitudes of load and strain sensors were recorded for each cycle. A complete cycle was also recorded as a function of a linear progression whose common difference depends on the stress level and thus fatigue test duration. The last 20 cycles before breaking were also systematically recorded.

\subsubsection{Dynamic Mechanical Analysis (DMA)}

DMA tests were performed on a Metravib DMA+300 device under tensile configuration. The distance between grips was $40 \mathrm{~mm}$. A static displacement of $18 \mu \mathrm{m}$ and a dynamic displacement of $3 \mu \mathrm{m}$ were applied on the sample at different frequencies (varying between 1 and $100 \mathrm{~Hz}$ ). The temperature sweep band is in a range between $40^{\circ} \mathrm{C}$ and $200{ }^{\circ} \mathrm{C}$ with $5^{\circ} \mathrm{C}$ steps. The heating rate is $0.03{ }^{\circ} \mathrm{C} \cdot \mathrm{s}^{-1}$. Two replicates were used to confirm the results we present here.

\subsubsection{In situ monitoring}

$\underline{\text { Infrared thermography (IR) }}$

An IR camera was also utilized to measure the variation of the test specimen surface temperature in-situ and in real time. The device used in this work was a Mid-Wavelength InfraRed camera, with a spectral response 
covering the range from 3-5 $\mu \mathrm{m}$ (MWIR3 JADE from the CEDIP Company). The detector spatial resolution was $320 \times 256$ pixels and the temperature sensitivity was approximately $25 \mathrm{mK}$ at $30^{\circ} \mathrm{C}$. The IR camera was synchronized to the mechanical test controller in order to trigger the acquisition of images. The frame rate speed varies between $0.1 \mathrm{~Hz}$ and $10 \mathrm{~Hz}$ according to the stress level.

A rectangular region of interest (ROI) of $180 \times 20$ pixels (or $120 \times 13 \mathrm{~mm}$ ) was defined on each image to measure the mean temperature at the surface of the specimen.

\section{Acoustic emission (AE)}

The monotonic and fatigue tests were also instrumented with acoustic emission measurements. A two-channel data acquisition system (Euro Physical Acoustics, MISTRAS Group) was used. This system comprises miniature piezoelectric sensors $(\mu-80)$ with a resonance frequency ranging from $250-325 \mathrm{kHz}$, preamplifiers with a gain of $40 \mathrm{~dB}$, a $20-1000 \mathrm{kHz}$ filter, a PCI card with a $5 \mathrm{MHz}$ sampling rate. The sensors were coupled onto the specimen faces using silicone grease. They were placed at the gauge extremities with a distance of 140 $\mathrm{mm}$ between their centres. System calibration was performed after installing the transducers on the specimen and before each test, using a pencil lead breaks procedure.

AE signals treatment and data processing and interpretation were done using a methodology and a software which were developed in the FEMTO-ST laboratory during the last years to analyse and interpret AE data when collected in complex experimental configurations, such as during fatigue tests. The methodology is particularly appropriated when facing continuous acoustic emissions, as encountered for example, in highly emissive materials due to their nature, the geometry or to high-frequency cycling such as considered in this paper. The methodology described in [39] relies on three steps: (i) a real time AE data streaming acquisition, (ii) AE hits' determination and separation, and (iii) conventional AE features extraction (MARSE energy, amplitude, average frequency, root mean square, average signal level, count-to-peak, reverberation frequency, initiation frequency, signal strength, absolute energy, partial power in [0 250] kHz, [250 500] kHz, [500 750] kHz and [750 1000] kHz, centroid frequency, peak frequency and weighted peak frequency). The efficiency of this methodology stems from the use of the discrete-wavelet transform using high-order Daubechies (db45) wavelets with 14 levels of decomposition. Wavelets are particularly well suited to analyse non-stationary signals where the frequency content evolves over time. Daubechies wavelets are highly asymmetric likewise AE signals. Using high-order Daubechies wavelets allows to get smoother wavelets and provides sharper frequency resolution. The use of a high number of levels of decomposition aims at locating AE signal onsets which are then used to extract the signals in the raw streaming before feature extraction. Such a procedure allows to drastically lower the threshold in hits determination (here $35 \mathrm{~dB}$ even with a cycling frequency equal to $30 \mathrm{~Hz}$ ). The timing parameters: PDT (Peak Definition Time) $=60 \mu \mathrm{sec}$; HDT (Hit Definition Time) $=120$

$\mu \mathrm{sec}$ and HLT (Hit Lock Time) $=300 \mu$ sec were identified by means of preliminary calibration measurements using pencil lead breaks.

\section{RESULTS AND DISCUSSION}

\subsection{Monotonic tensile behaviour}

The stress-strain response of the UD flax-epoxy composite material tested in this study under tensile monotonic loading up to failure is represented in Figure 2(a). The material clearly exhibits a nonlinear behaviour and more exactly a bi-phasic behaviour. The nonlinearity is now well-accepted and documented for flax-epoxy composites [2, 4, 40, 41]. For the tape-based material tested in this study, the modulus-strain curve (see Fig. 2(b)) exhibits two regions: (i) a strain softening between the loading start point and a yield point located in a strain range from 0.15 to $0.2 \%$, (ii) a linear region from this yield point to almost the composite failure. At a standard head displacement rate of $2 \mathrm{~mm} \cdot \mathrm{min}^{-1}$, the mean values of longitudinal apparent modulus $\left(\mathrm{E}_{L}{ }^{m 1}\right)$, strength $\left(\boldsymbol{\sigma}_{\mathrm{L}}\right)$ and strain at failure $\left(\boldsymbol{\varepsilon}_{\mathbf{L}}\right)$ are approximately $35 \mathrm{GPa}, 387 \mathrm{MPa}$, and $1.52 \%$. These values are in good agreement with the datasheet of the material provider and with data of literature collected on the same type of UD flax-epoxy composites [42, 43]. Fig. 2 and Tab.1 also show that the scattering between the different specimens tested at a same loading rate is very low, with a coefficient of variation (CoV) inferior to $10 \%$ for all the tensile properties. It confirms the high-grade of the material and the reproducibility of the manufacturing 
process. The material was also tested in the transverse direction using three-point bending tests. The mean values measured are $3.3 \mathrm{GPa}, 20.2 \mathrm{MPa}$, and $0.93 \%$ for the transverse apparent modulus $\left(\mathrm{E}_{T}{ }^{m 1}\right)$, strength $(\mathbf{T})$ and strain at failure $\left(\boldsymbol{\varepsilon}_{\mathbf{T}}\right)$ respectively. These values are in good agreement with the works by Perremans et al. [44]. This paper reports three-point bending strength comprised between approximately 12 to $30 \mathrm{MPa}$ for UD flax/epoxy composites, depending on the treatment applied on fibres before composite manufacturing.

(a)

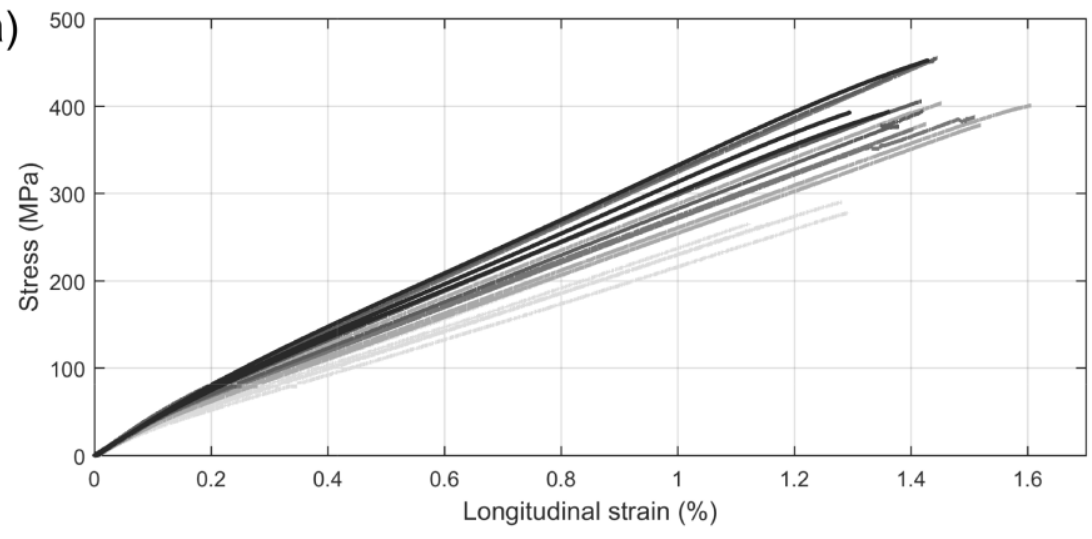

(b)

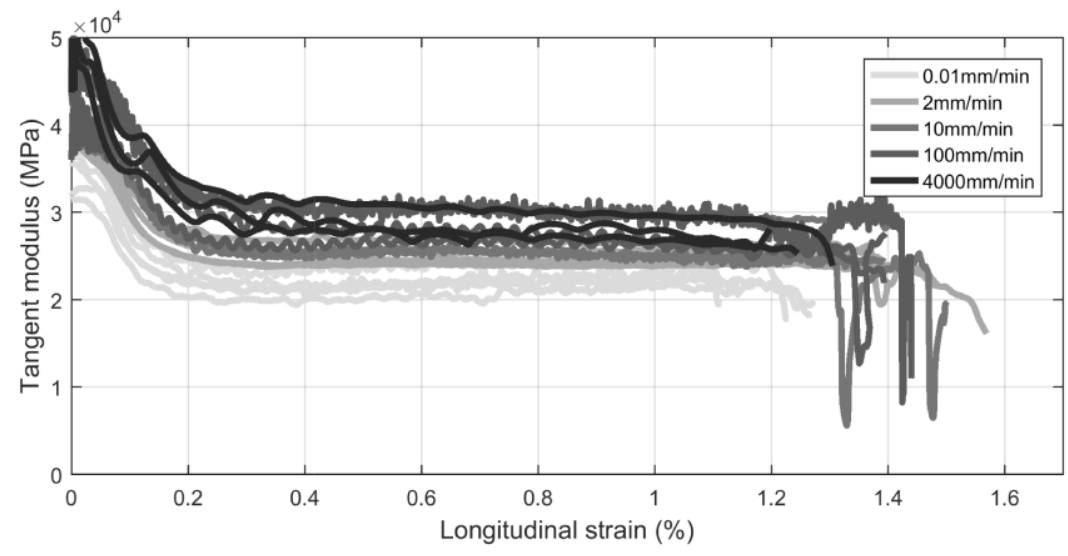

Figure 2: Tensile curves of the specimens tested in the fibre direction at five different moving crosshead speeds (0.01 mm.min ${ }^{-1}, 2$ mm.min $\left.{ }^{-1}, 10 \mathrm{~mm} . \mathrm{min}^{-1}, 100 \mathrm{~mm} . \mathrm{min}^{-1}, 4000 \mathrm{~mm} . \mathrm{min}^{-1}\right)$. a: stress-strain curves, b: apparent tangent modulus-strain curves 
Table 1: Properties in longitudinal direction obtained under monotonic tensile tests up to failure (mean value \pm standard deviation)

\begin{tabular}{|c|c|c|c|c|}
\hline $\begin{array}{c}\text { Loading speed } \\
\left(\mathbf{m m} \cdot \mathbf{m i n}^{-1}\right)\end{array}$ & $\begin{array}{c}\text { Tensile } \\
\text { strength } \\
\boldsymbol{\sigma}_{\mathbf{L}}(\mathbf{M P a})\end{array}$ & $\begin{array}{c}\text { Tensile strain } \\
\text { at failure } \\
\boldsymbol{\varepsilon}_{\mathbf{L}}(\boldsymbol{\%})\end{array}$ & $\mathbf{E}_{\boldsymbol{L}}^{\boldsymbol{m} \mathbf{1}}(\mathbf{G P a})$ & $\mathbf{E}_{\boldsymbol{L}}^{\boldsymbol{m} \mathbf{2}}(\mathbf{G P a})$ \\
\hline 0.01 & $279 \pm 21$ & $1.18 \pm 0.1$ & $30.9 \pm 2.3$ & $22.7 \pm 1.5$ \\
\hline 2 & $387 \pm 12$ & $1.52 \pm 0.09$ & $35 \pm 0.8$ & $24.6 \pm 0.8$ \\
\hline 10 & $402 \pm 30$ & $1.45 \pm 0.06$ & $38.2 \pm 3.1$ & $26.4 \pm 2.1$ \\
\hline 100 & $407 \pm 23$ & $1.43 \pm 0.02$ & $38.6 \pm 2.6$ & $33.7 \pm 7.2$ \\
\hline 4000 & $412 \pm 31$ & $1.35 \pm 0.08$ & $42.0 \pm 2.7$ & $28.9 \pm 1.5$ \\
\hline
\end{tabular}

Table 2: Properties in transverse direction obtained under three point bending tests up to failure (mean value \pm standard deviation)

\begin{tabular}{|c|c|c|}
\hline $\begin{array}{c}\text { Flexural } \\
\text { strength } \\
\boldsymbol{\sigma}_{\mathbf{L}}(\mathbf{M P a})\end{array}$ & $\begin{array}{c}\text { Flexural strain } \\
\text { at failure } \\
\boldsymbol{\varepsilon}_{\mathbf{L}}(\boldsymbol{\%})\end{array}$ & $\mathbf{E}_{\boldsymbol{L}}^{\boldsymbol{m} \mathbf{1}}(\mathbf{G P a})$ \\
\hline $20.2 \pm 2.3$ & $0.93 \pm 0.1$ & $3.3 \pm 0.03$ \\
\hline
\end{tabular}

\subsection{Influence of speed on the monotonic tensile behaviour}

The S-N curves are generally built by applying a maximum load equal to given ratios of the mean quasi-static tensile failure stress. So, before investigating the influence of frequency on the fatigue behaviour, we studied the influence of the loading rate on the monotonic behaviour up to failure. Five constant crosshead speeds were used, ranging from 0.01 to $4000 \mathrm{~mm} \cdot \mathrm{min}^{-1}$, corresponding to an average strain rate $10^{-6}$ to $410^{-1} \mathrm{~s}^{-1}$. Figure 2 shows that the loading rate has no significant effect on the shape of the nonlinearity for the whole range of speeds. On the range from 2 to $4000 \mathrm{~mm} \cdot \mathrm{min}^{-1}$, the loading rate has also a small influence on the monotonic tensile properties. As a whole, the mean strength and initial rigidity $\left(\mathrm{E}_{L}{ }^{m 1}\right)$ slightly increase with increasing loading rate, from 387 to $412 \mathrm{MPa}$ and from 35 to $42 \mathrm{GPa}$, respectively. On the range from 0.01 to $2 \mathrm{~mm}$.min , the trend is more pronounced with a change from 279 to $387 \mathrm{MPa}$ and from 30.9 to $35 \mathrm{GPa}$ for the mean tensile strength and initial rigidity $\left(\mathrm{E}_{L}{ }^{m 1}\right)$ respectively. This strain-rate sensitivity is generally expected for polymeric materials and is comprehensively consistent with the results of Poilâne et al. [40] collected on a quasi-unidirectional material for a strain rate range from $10^{-5}$ to $10^{-9} \mathrm{~s}^{-1}$. Regarding the strain at failure, no significant difference was observed, except at $0.01 \mathrm{~mm} \cdot \mathrm{min}^{-1}$, where the strain at failure is approximately $20 \%$ lower when compared to the other speeds. 


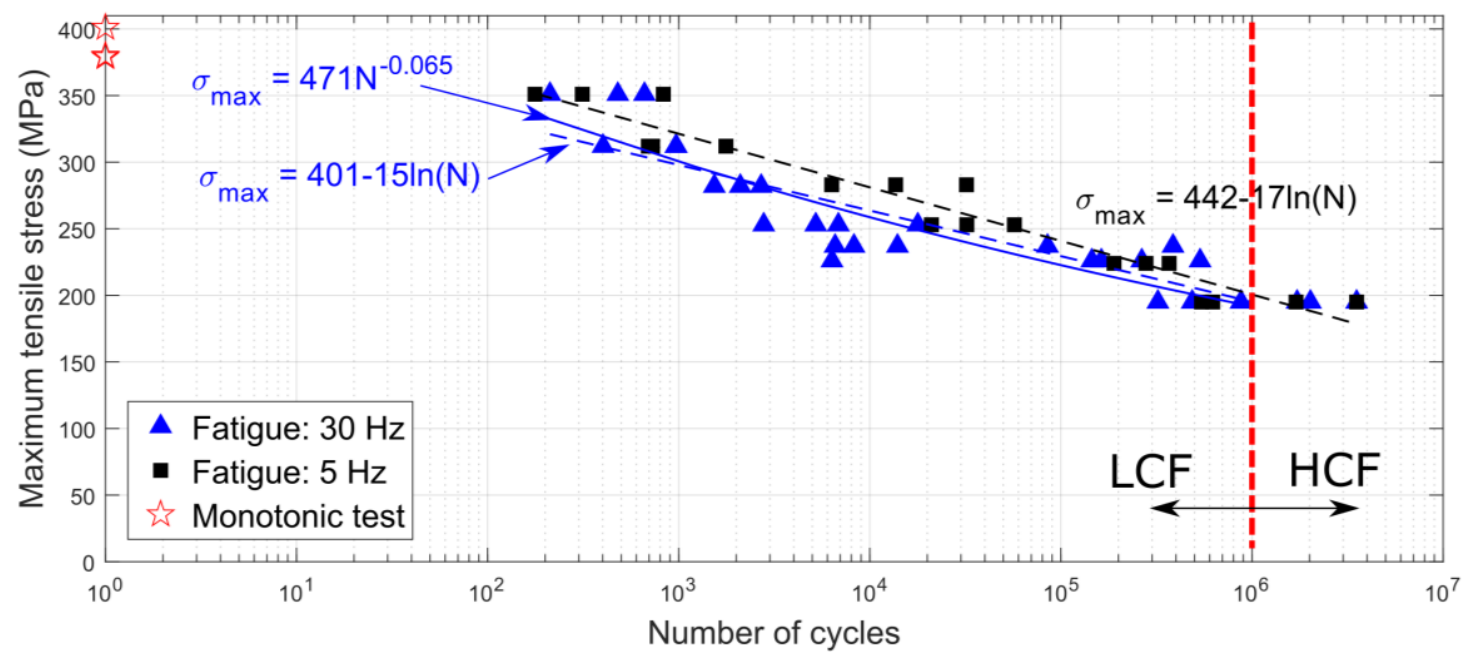

Figure 3: S-N curves collected at two loading frequencies, $5 \mathrm{~Hz}$ and $30 \mathrm{~Hz}$.

\subsection{Tensile-tensile fatigue behaviour}

S-N curves for tensile-tensile fatigue tests at $5 \mathrm{~Hz}$ and $30 \mathrm{~Hz}$ are presented in Fig. 3. These results concern mainly the LCF range. Results show that both sets of specimens present a gradual decline in fatigue strength with increasing number of fatigue cycles. For a given loading level, dispersion in fatigue life duration is observed. The order of magnitude of this dispersion is in agreement with data from literature collected on flaxepoxy laminates $[2,3,7,9,10]$, except for 253 and $237 \mathrm{MPa}$ (65\% and $61 \%$ of the monotonic tensile strength), for which a high scattering in number of cycles at failure is observed.

The fatigue strength as a function of number of cycles can be fitted by a logarithmic law (Eq. 3), as well as by a power-law curve (Eq. 4):

$S_{\max }=\alpha-\beta \ln (N)$

$S_{\max }=S_{0} N^{b}$

The best fit is obtained with a logarithmic law. The identified $\beta$ parameter is lower when compared to the value obtained by Bergès et al. [4] (17 vs. 20) on a quasi-UD flax-epoxy composite, traducing a better resistance to fatigue. Indeed, the fatigue strength for $10^{6}$ cycles is approximately $200 \mathrm{MPa}$. It represents approximately $52 \%$ of the monotonic tensile strength, which is almost 10 percentage points higher than the value obtained in $[4,7]$. Again, it shows the high-grade of the material.

\subsection{Influence of frequency on the tensile-tensile fatigue behaviour in LCF range}

Regarding the loading frequency, it can be observed that the S-N curves recorded at 5 and $30 \mathrm{~Hz}$, respectively, are quite similar. The maximum stress for a fatigue life of $10^{6}$ cycles is approximatively the same (around 200 $\mathrm{MPa}$ ) for the two loading frequencies. For the $\mathrm{S}-\mathrm{N}$ curve collected at $30 \mathrm{~Hz}$, a best fit can be obtained with a power-law model (Eq. 4). A $b$ value of -0.064 was identified. This value is in the range from- 0.0739 to -0.0623 given by Shah et al. [12] for various PFCs. However, this power-law trend is mainly due to the low number of cycles to failure recorded at 312,282, 253 and $237 \mathrm{MPa}(80,72.5,65$ and $61 \%$ of the mean quasi-static strength, respectively) when compared to the other loading levels. For the highest (90\%) and the lowest (57.5 and 50\%) loading levels tested in this part of the study, the experimental points are roughly comprised within a same number of cycles range for 5 and $30 \mathrm{~Hz}$. In contrast, for 312, 282, 253 and $237 \mathrm{MPa}$, Fig. 3 shows that the 30 $\mathrm{Hz}$ data points are roughly shifted towards lower number of cycles. This is particularly marked at 282, 253 and $237 \mathrm{MPa}$. At $282 \mathrm{MPa}$, the lifetime is comprised between 1,500 and 3,200 cycles at $30 \mathrm{~Hz}$, when it is between 6,300 and 32,000 cycles at $5 \mathrm{~Hz}$. In the same way, we measured a range from 2,700 to 18,000 cycles at $30 \mathrm{~Hz}$ 
and from 21,000 to 57,000 cycles at $5 \mathrm{~Hz}$ for $253 \mathrm{MPa}$. At $312 \mathrm{MPa}$, the gap is lower and the cycle ranges are 400 to 1,000 cycles and 600 to 1,700 cycles at 30 and $5 \mathrm{~Hz}$, respectively.

As often hypothesized or measured in literature for organic matrix composites, this slight decrease in the fatigue lifetime for these loading levels could be attributed to the self-heating of the specimens. So, this issue was investigating within this work by measuring the mean temperature at the specimens' surface using infrared thermography.
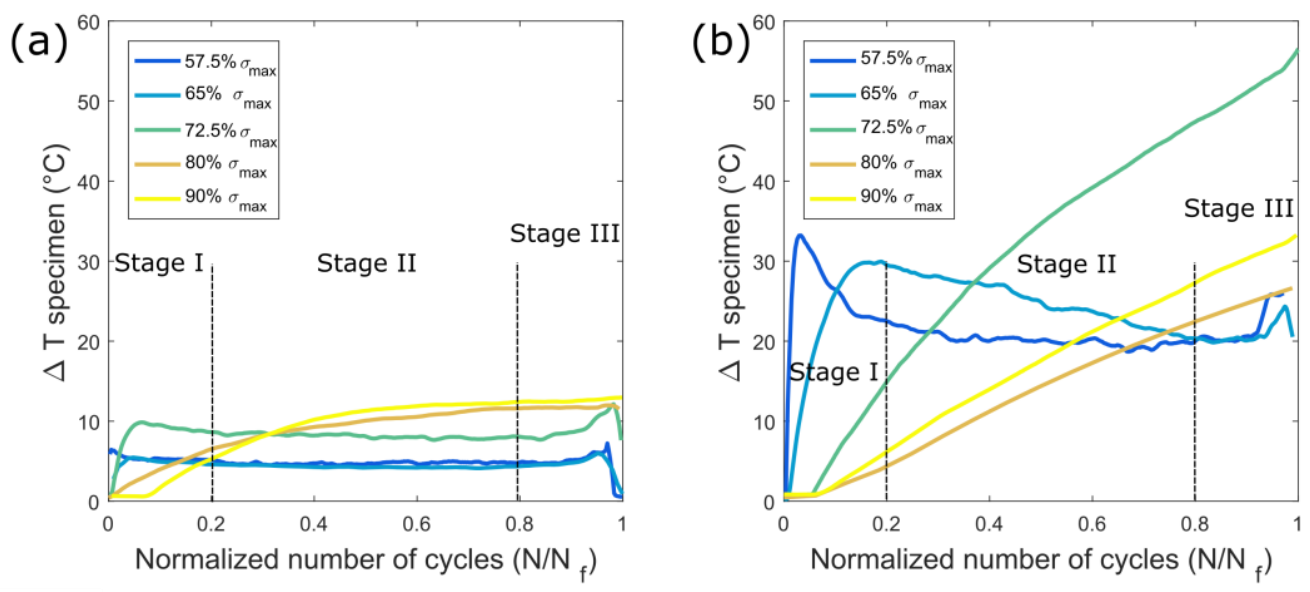

Figure 4: Evolution of the mean temperature increase measured at the surface of the specimens using IR thermography during fatigue tests at a frequency of $5 \mathrm{~Hz}$ (a) and $30 \mathrm{~Hz}$ (b).

\subsubsection{Self-heating}

Fig. 4 gives the evolution of the mean temperature increase measured at the surface of the specimens using IR thermography during fatigue tests at 5 and $30 \mathrm{~Hz}$. At $5 \mathrm{~Hz}$, results show that the limitation stipulated by the standards, in terms of temperature increase (i.e. $\Delta \mathrm{T}<10^{\circ} \mathrm{C}$ ), is almost respected, with a maximum temperature increase of approximately $13^{\circ} \mathrm{C}$. On the contrary, for $30 \mathrm{~Hz}$, the self-heating level is significantly higher with a maximum mean temperature increase at the specimens' surface that can reach almost $55^{\circ} \mathrm{C}$. It leads to a mean temperature at the surface of the specimen of approximately $78^{\circ} \mathrm{C}$ (tests being performed at room temperature). Fig. 5 provides a thermal imaging at the surface of the specimen during fatigue tests. It points out that the thermal field is heterogeneous, with a maximum temperature that can reach $83^{\circ} \mathrm{C}$ locally. This heterogeneity originates probably from the stress field heterogeneity, coming itself from the cumulated damage in the specimen. The appearance of splitting, growing in the longitudinal direction, was particularly observed during the tests. This type of damage disrupts the load transfer to fibres in the specimen's width. It can explain that on Figure 5 the temperature on the right edge of the specimen is low (approximately $40^{\circ} \mathrm{C}$ ) when compared to the left edge. 


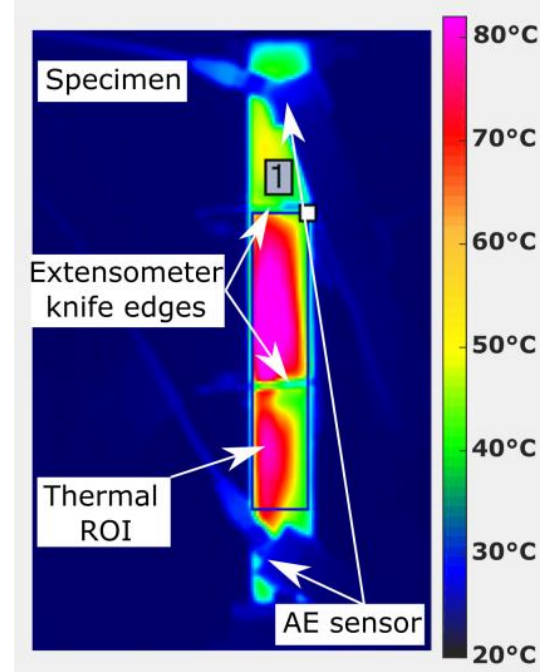

Figure 5: Thermal variations of the specimen before failure recorded by infrared camera.

Thus, the temperature increase level depends on the maximum stress level as well as the position within the sample. The maximum self-heating is not obtained for the highest stress level but for intermediary levels, 237 to $282 \mathrm{MPa}$, leading to number of cycles at failure comprised between $210^{3}$ and $210^{4}$. Indeed, the self-heating depends on the maximum stress level and also on the cycling duration which is related to the time necessary to dissipate heat. On Fig. 4, at $5 \mathrm{~Hz}$, it can be observed that, for the considered stress levels, temperature starts to increase significantly at the first stage of the fatigue tests and beyond a given limit reaches a steady state where the temperature stabilizes. A sudden increase in temperature can also be observed in the last stage, just before failure. For $30 \mathrm{~Hz}$, the trends are quite different. For the low loading levels, the trend is the same for the first fatigue stage, but in the second phase (steady state), instead of stabilizing, the temperature slowly decreases. For the highest loading levels, the temperature continuously increases up to failure. No plateau can be observed. The cycling time is not enough to reach a steady state. As a consequence of this particular thermomechanical behaviour, the maximum recorded temperature is obtained for the intermediary loading levels, for which the cycling time is long enough to approach the steady state plateau.

This particular self-heating behaviour may reduce the lifetime measured for the specimen tested at 312, 282, 253 and $237 \mathrm{MPa}$ at $30 \mathrm{~Hz}$. Indeed, the maximum temperature at the specimen's surface for these points reaches values up to approximately $85^{\circ} \mathrm{C}$, corresponding to the onset of the softening zone. Effectively, even if the glass transition temperatures of the neat resin and composite are approximately $130^{\circ} \mathrm{C}$ (Fig. $6 \mathrm{a}$,b), the transition range is quite large and the onset of the softening peak is approximately 85 to $95^{\circ} \mathrm{C}$, depending on the loading frequency. These values were determined using DMA tests performed using tensile tests in the fibre direction. DMA results show that, only slight variations in the elastic and damping properties are observed up to $85^{\circ} \mathrm{C}$ when compared to $23^{\circ} \mathrm{C}$ (Fig. $6 \mathrm{c}$,d). A maximum decrease of approximately $6 \%$ in storage modulus and an increase of $19 \%$ in loss factor are measured on this temperature range. Above $85^{\circ} \mathrm{C}$, the change in elastic and damping properties per increasing ${ }^{\circ} \mathrm{C}$ can be significant, up to $0.25 \mathrm{GPa} /{ }^{\circ} \mathrm{C}$ and $0.3 \% /{ }^{\circ} \mathrm{C}$ for the elastic and damping properties respectively. So, it can be assumed that when a temperature of $85^{\circ} \mathrm{C}$ is measured at the specimen's surface, a highest temperature does exist in the core of the specimen, meaning that a part of the material volume approaches the peak of $\mathrm{Tg}$ and then exhibit lower elastic properties and a highest damping capacity.

Anyway, it can also be concluded that for the other fatigue levels the temperature in the specimen is significantly lower than the onset of the softening temperature, and that no significant variation in elastic and damping properties occurs within the specimen. 
(a)
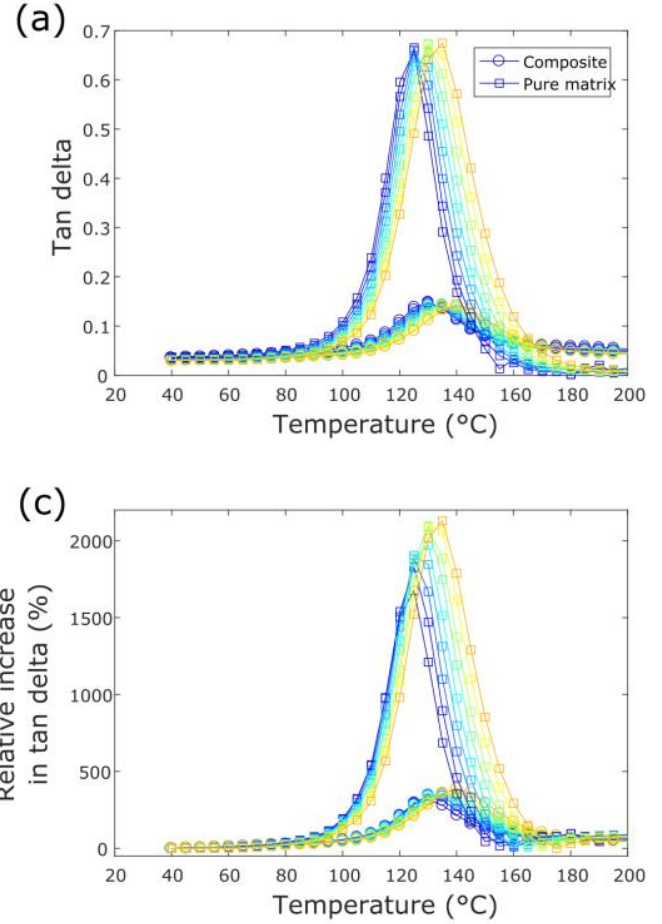

(b)
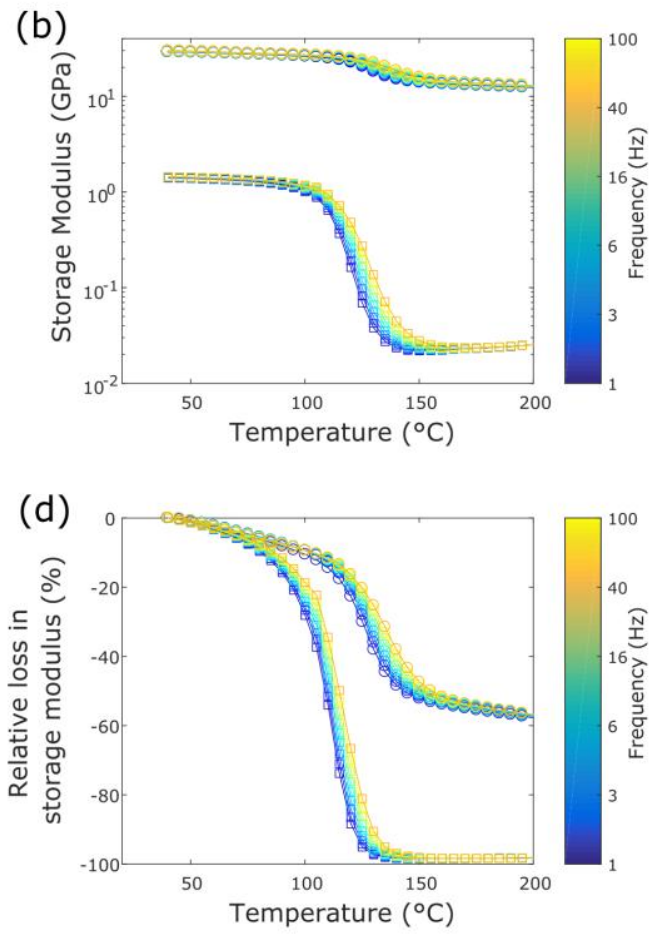

Figure 6: Evolution of the tan delta (a) and of the storage modulus (b) as a function of temperature for the neat resin and the composite. Relative increase in tan delta (c) and relative loss in storage modulus (d). Results collected from DMA tests at frequencies between 1 and $100 \mathrm{~Hz}$.

\subsubsection{Hysteresis loops}

Fig. 7 shows the hysteresis loops for different life fraction and loading levels at 5 and $30 \mathrm{~Hz}$. From these loops, two main features related to the inelastic behaviour can be identified as well as their evolution as a function of the cycle number: the mean strain and the dissipated energy. These are determined from the mean strain amplitude and from the area of the hysteresis loop, respectively. Both features are resulting from the expression of time-delayed and irreversible phenomena related to viscoelasticity, stiffening phenomena and damage.

Fig. $8 \mathrm{a}$ and $8 \mathrm{~b}$ give the evolution of the dissipated energy as a function of the life fraction. The trend can be split into three stages with a significant decrease in dissipated energy during the first stage, a constant dissipated energy during the second stage and significant increase during the last stage. This trend and the levels are not notably affected by the loading frequency, except for the first stage where no decrease where recorded except for the lower stress level (224 MPa). 

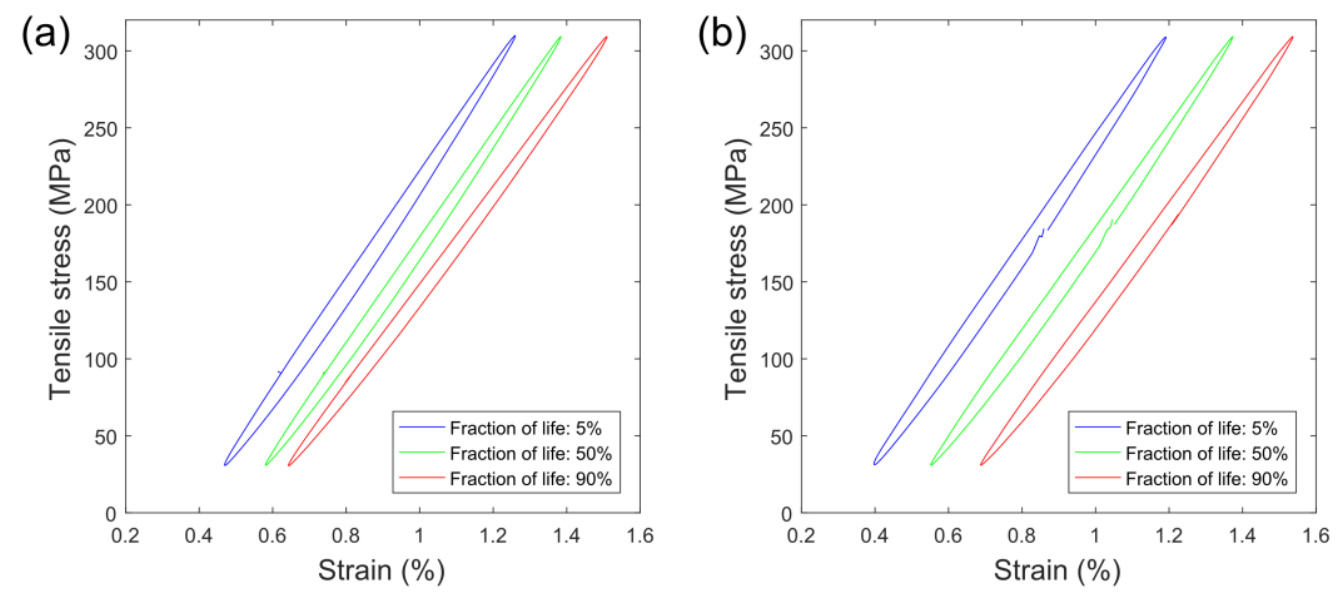

Figure 7: Hysteresis loops for different life fraction $(5,50,90 \%)$ at $5 \mathrm{~Hz}$ (a) and $30 \mathrm{~Hz}(\mathrm{~b})$, for a stress

level of $80 \%$ of the static stress at failure.

\subsubsection{Creep-like behaviour}

Results also show that the mean strain increases as function of the increasing number of cycles for both frequencies (Fig. 8c and 8d). A more precise representation is given in Fig. $8 \mathrm{c}$ and $8 \mathrm{~d}$, where the mean strain is plotted as a function of the life fraction for the different tested loading levels. At $5 \mathrm{~Hz}$, for all the loading levels, the mean strain significantly increases until a life fraction comprised between 0.05 and 0.1 . Following this increasing, the mean strain reaches a second stage where the strain steal increases but with a lower rate. The rate is all the more important that the stress is high. Just before failure (final fatigue stage), a sudden increasing is observed.

The influence of loading frequency on this creep-fatigue behaviour is not really substantial. The initial mean strain is approximately the same than at $5 \mathrm{~Hz}$ for the different loading levels. Only the strain rate in the second fatigue stage is slightly higher when compared to $5 \mathrm{~Hz}$, leading also to a higher mean strain at failure.

This general increase in mean strain as a function of fatigue cycles, generally described as a creep-like behaviour, can be attributed to a time-dependent behaviour of this material in the fibre direction. Indeed, in plant based, both matrix and fibres can develop viscoelastic. It leads to a significant creep-fatigue interaction. These residual strains can also be attributed to irreversible behaviour such as damage or plasticity.

\subsubsection{Stiffening}

PFCs exhibit two specificities that are generally not observed (or in a lower extent) for glass and carbon fibre composites: fatigue-creep and stiffening under cyclic loading [3,45]. Indeed, it is now well-accepted that these UD PFCs exhibit stiffness increase under cyclic loading $[3,4,11]$. As for the nonlinear tensile monotonic behaviour, its origins are widely debated in the scientific community. It was attributed to various phenomena, at different scales, such as flax fibre strain-hardening or fibre re-orientation. For this pure UD material, the hypothesis of fibre reorientation in twisted yarns is not valid, and thus the hypothesis of the strain-hardening of the fibre itself is, once more, the most relevant. Indeed, plant fibres have been observed to become stiffer when they are submitted to cyclic tensile loading [46-48]. In previous works, we proposed a scenario that is based on time-dependent re-orientation of cellulose microfibrils and stress-induced crystallization of amorphous cellulose in the fibre wall $[47,49]$. We also experimentally demonstrated that the fibre stiffening under cyclic loading is dependent on the loading frequency [50].

The time-dependency of the stiffening phenomenon was also investigated during the fatigue tests. To compare the results collected at different stress levels, the normalised dynamic modulus $\left(\mathrm{E}_{\mathrm{L}}^{*} / \mathrm{E}_{\mathrm{L}}^{*}\right)$ and number of cycles 
$\left(\mathrm{N} / \mathrm{N}_{\mathrm{f}}\right)$ curve method is preferred, as often used in literature [16]. Based on the results collected within this study, it appears the flax-epoxy composite stiffening is also dependent on the loading frequency, as recently observed in literature [51]. Figure 8 (e and $\mathrm{f}$ ) shows the evolution of the normalized dynamic modulus as a function of the life fraction at different loading levels and for the two tested frequencies. At $5 \mathrm{~Hz}$, we observe a progressive increase of the dynamic modulus as a function of increasing number of cycles, up to a plateau, and before a significant decrease occurring in the last stages just before failure. This final decrease is attributed to damage. On the plateau (second stage of the fatigue life), the increase in modulus varies from 2 to $14 \%$, depending on the maximum stress level which was applied. For $30 \mathrm{~Hz}$, the same trend is only observed for the lower stress (224 MPa) with a maximum stiffening of approximately $12 \%$. For the other loading levels, the modulus starts to slightly increase first and then reverses to decrease slightly and continuously with the increasing number of cycles. In the third stage, as for $5 \mathrm{~Hz}$, a sharp decrease in stiffness precedes the failure. Before entering in this third stage, the decrease in stiffness does not exceed 10\% (when compared to the initial value).

On the fringes of the issue raised in this study, it is worth noting that whatever the stress level and the loading frequency and before the final fatigue stage, the stiffness varies slightly, by a factor of 1.14 to 0.95 when compared to its initial stiffness. It means that in addition to its good fatigue resistance, this material has also a good capacity to maintain its rigidity under cyclic loading.

The next paragraph proposes a detection and characterisation of damage during fatigue tests using acoustic emission.
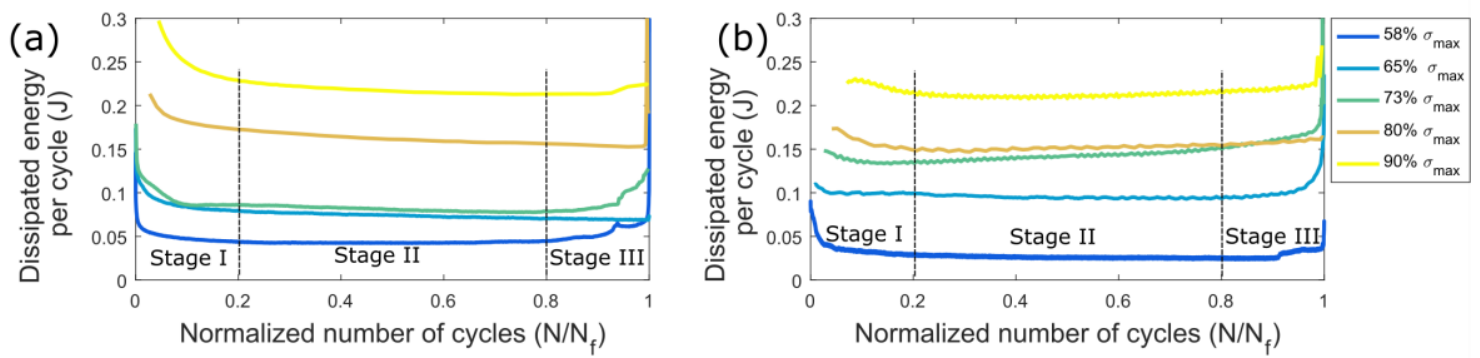

(c)
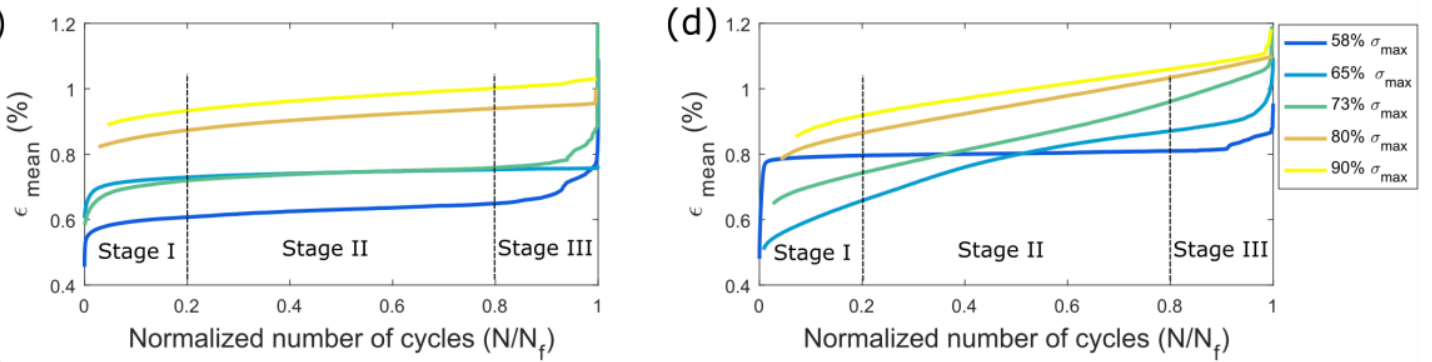

(e)
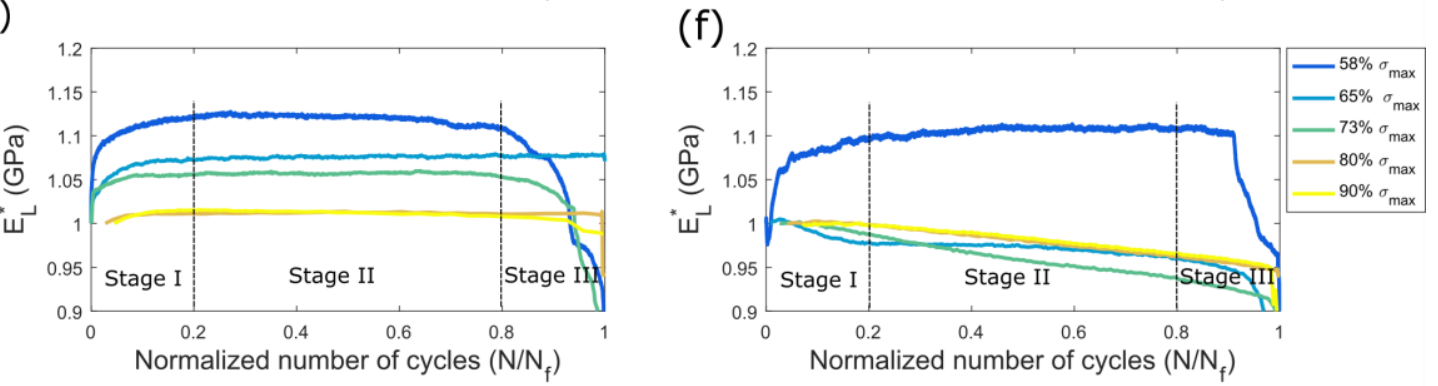

Figure 8: Dissipated energy (a, b), mean strain (c, d), and normalised dynamic modulus (e, f), recorded for a testing frequency of 5 and $30 \mathrm{~Hz}$ respectively. 


\subsubsection{Damage}

The number of acoustic emission events and the associated acoustic energy were computed for all the tested specimens. Figure 9 gives the evolution of the normalized number of events and cumulated acoustic energy as a function of the life fraction (current cycle divided by the number of cycles at failure) for the different tested loading level and frequencies. Three specimens were tested at each level of stress. Figure 10 synthetises the cumulated values of these features recorded for each fatigue frequency as a function of the number of cycles at failure. It can be observed that the values of the cumulated acoustic energy and the number of AE events at failure slightly increase with the increasing number of cycles at failure. This can be due to the AE activity originating from the cumulated damages, such as friction at the interface between the lips of cracks (crack opening and closure) or split areas. Indeed, in the AE methodology used in this work, the detected AE events can originate from the damage creation and propagation as well as the presence of the generated defects. Interestingly, it can be observed that the values of the cumulated acoustic energy and the number of AE events at failure are comparable for the two tested fatigue frequencies. It reflects that the damage activity, for such a material, is not influenced by the loading frequency, at least for the frequency range considered in this work. It can also be underlined, that based on these results, and in particular on the linear relationship between these AE features and the number of cycles at failure, the lifetime of this material could be directly estimated from the number of AE events and cumulated acoustic energy.

Fig. 9 also provides, for each test, information regarding the AE activity kinetic. It reflects the evolution of the damage activity as a function of the number of cycles. It appears that at $5 \mathrm{~Hz}$ the main three stages of the fatigue lifetime can be observed from the kinetics of the acoustic emission (AE) activity and cumulated energy. In the first stage (below a life fraction of 0.1), both the activity and the released $\mathrm{AE}$ energy increase following a logarithm trend. The activity and cumulated energy general do not exceed $20 \%$ of the final cumulated value. This activity could be related to the microstructural mechanisms related to the stiffening phenomenon as well to damage. This stage is generally followed by a second one where the rate is more or less constant. The slope depends on the loading level, generally increasing with the increasing loading level. At last, a sharp increase both in activity and released energy is observed in stage 3 up to the failure. In this stage, AE events are attributed to the major damage that occurs just before failure (including fibre breakages).

At $30 \mathrm{~Hz}$, and particularly for AE activity, this trend is less pronounced and the activity is sometimes almost constant during the whole test. It reflects a more constant damage activity compared to $5 \mathrm{~Hz}$ which could hinder or counterbalance the stiffening phenomenon, explaining the decrease in rigidity as a function of the number of cycles observed at $30 \mathrm{~Hz}$.

As a conclusion of this part, even if the increase in the loading frequency (from $5 \mathrm{~Hz}$ to $30 \mathrm{~Hz}$ ) induces a decrease of the fatigue strength in the middle LCF range, it has no significant impact on the other parts of the S-N curve, neither on the early nor on the final part of this range. Even if the fatigue life is not affected, this does not mean, however, that creep-fatigue, damage kinetics and dynamic stiffening phenomenon are similar. Anyway, the prediction of HCFS seems achievable by increasing the loading frequency. Stakes are considerable since the increasing of the loading frequency from $5 \mathrm{~Hz}$ to $30 \mathrm{~Hz}$ makes the determination of the maximum stress for $10^{8}$ cycles realistic at the scale of lab tests, reducing the test duration from 231 days to 38 days. The last section of the study proposes an investigation of the HCF using an increased loading frequency of $30 \mathrm{~Hz}$. 

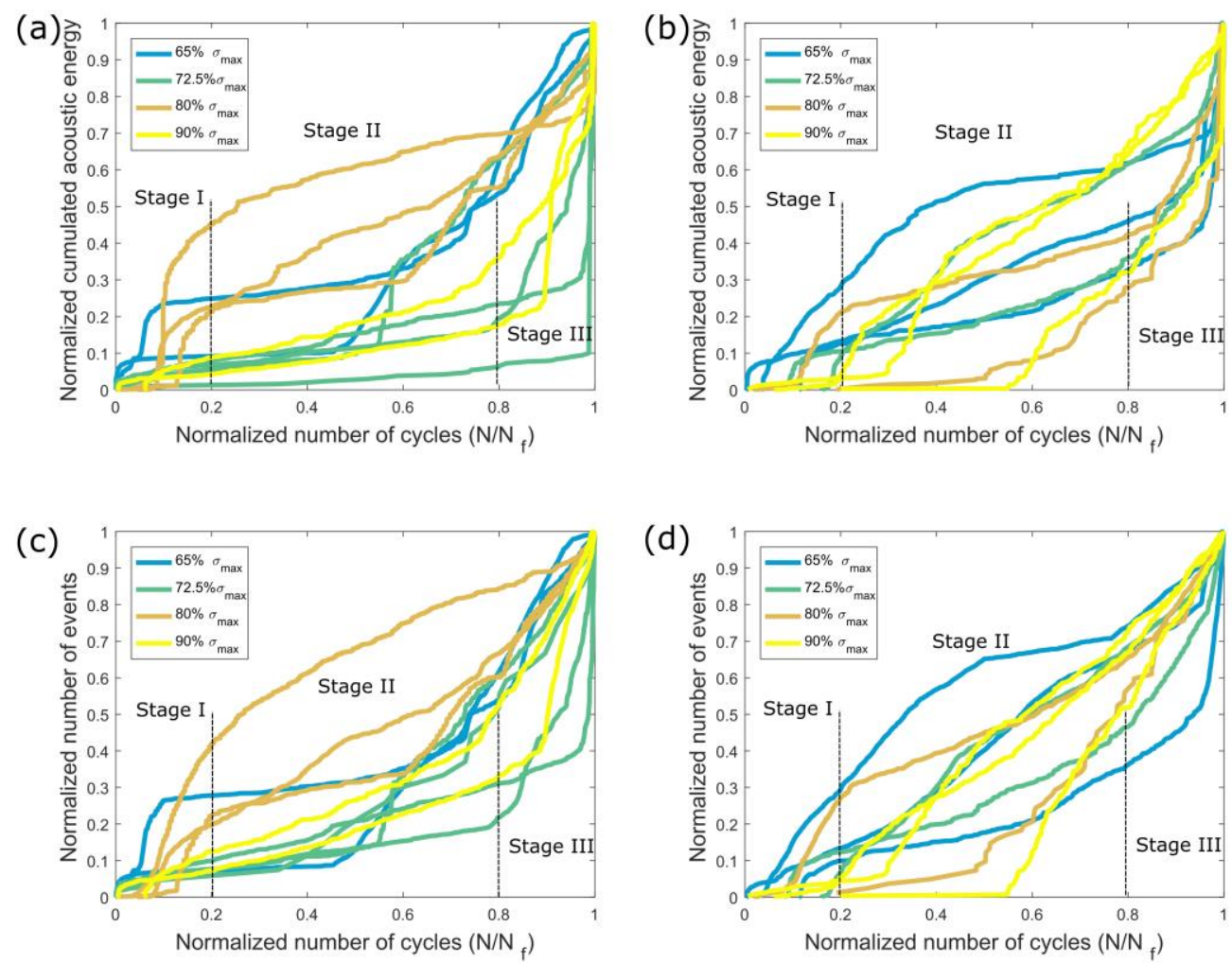

Figure 9: Normalized cumulated acoustic energy and number of event collected during fatigue tests at $5 \mathrm{~Hz}$ (a and c) and $30 \mathrm{~Hz}$ (b and d). Three specimens were tested at each level of stress.

(a)

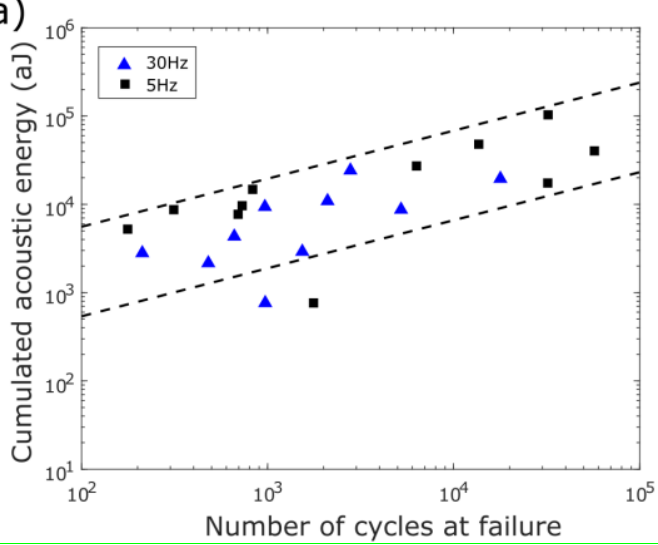

(b)

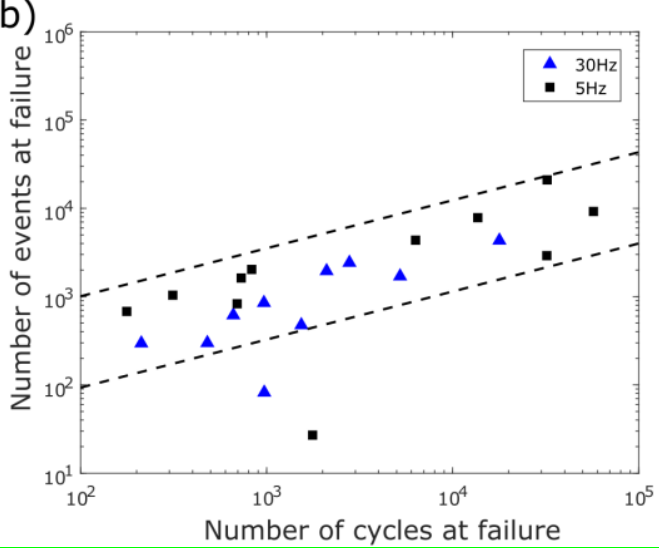

Figure 10: Acoustic emission results, number of events and cumulated acoustic energy as a function of the number of cycles at failure.

3.5. Investigation of the high-frequency HCF behaviour 
Figures 11 gives the S-N curve with data collected at 50, 45, 40 and $35 \%$ of the quasi-static tensile strength (meaning a maximum stress comprised between 195 and $136.5 \mathrm{MPa}$ ). It clearly shows for the first time that for this type of composite, in the fibre direction and under tension-tension loading (with a $\mathrm{R}$ ratio of 0.1 ), the maximum stress still decreases continuously as a function of the number of cycles. The trend is well predicted using the power law model identified from LCF tests. A maximum stress of approximately $140 \mathrm{MPa}$ is measured for $10^{8}$ cycles. This value has to be compared to the $200 \mathrm{MPa}$ obtained at $10^{6}$ cycles.

This result clearly shows that this material doesn't reach a fatigue limit and that a decreasing maximum stress as a function of the number of cycles has to be considered, at least up to $10^{8}$ cycles, when designing flax epoxy structures.

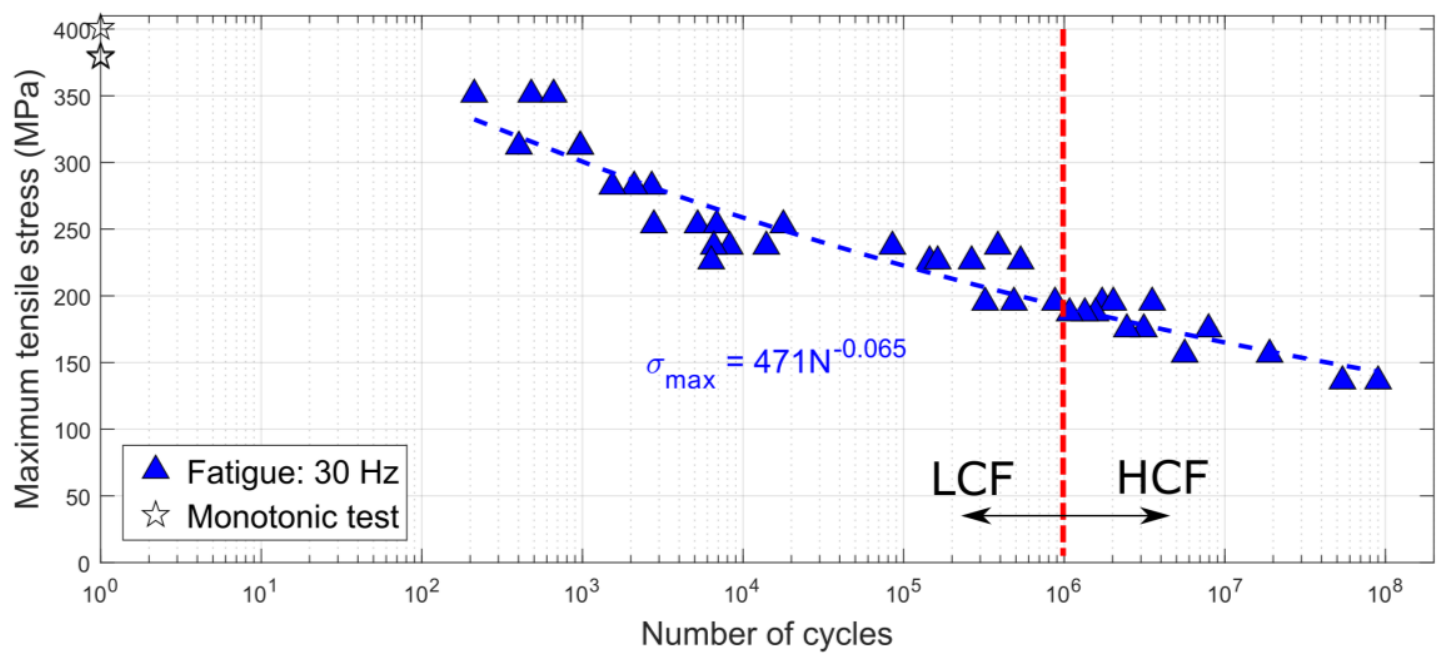

Figure 11: S-N curves collected at loading frequency of $30 \mathrm{~Hz}$.

Figure 12 shows the evolution of the mean strain, dissipated energy per cycle and normalised dynamic modulus as a function of the life fraction for these four fatigue levels. As for the LCF range, the level of the mean strain and dissipated energy decrease with decreasing stress levels. Interestingly, the dynamic modulus increases significantly during the first stage of the fatigue life, and even more so as the maximum stress level decreases. Figure 13 represents the maximum value of the stiffness increase measured during the fatigue life for the different stress levels. While no stiffening was observed at $30 \mathrm{~Hz}$ for the highest stress levels, it can be observed that, below $60-65 \%$ of the ultimate tensile stress, the stiffening can be observed. Its intensity increases with the decreasing maximum stress, as it was observed at $5 \mathrm{~Hz}$ on the whole LCF range. Fig. 12c that shows the apparent stiffness is stabilized up to one third to one life of the specimens' life. At this lifetime, a slight decrease in the apparent rigidity is observed. It corresponds probably to the apparition of damage in the material. In the second part of their life and after this event, the rigidity remains roughly constant. In the last stage (for life fractions between 0.9 and 1), sudden drops in rigidity can be detected. They were correlated to splitting in the specimen, observed visually. Despite these events, these composite materials never lose more that $5 \%$ of their initial stiffness during their own life in the HCF range. This is an outstanding results underlining their good HCF behaviour. 

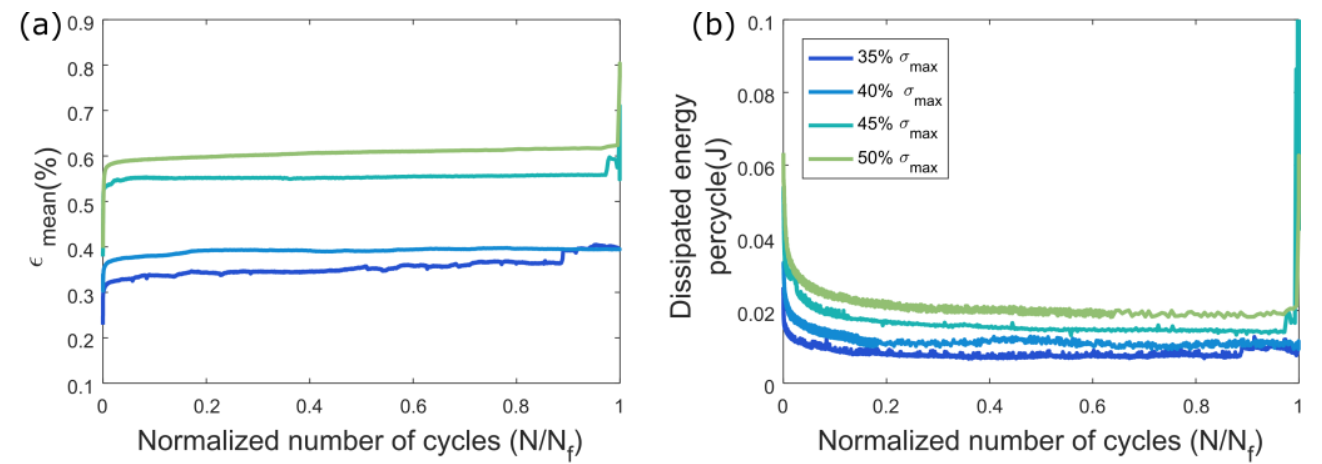

(c)

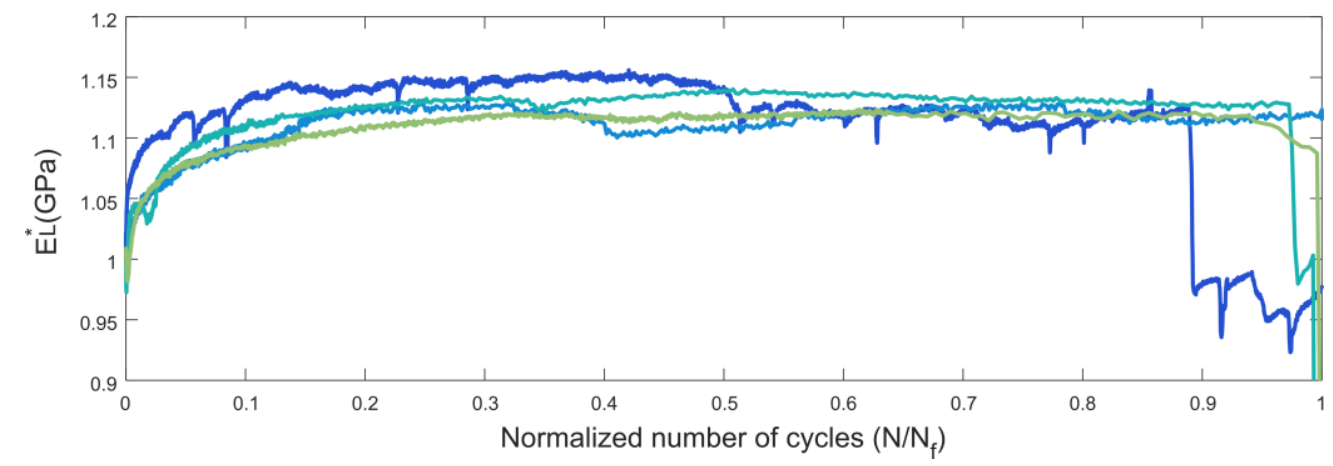

Figure 52: Mean strain (a), dissipated energy (b), normalised dynamic modulus (c), and recorded for a testing frequency $30 \mathrm{~Hz}$.

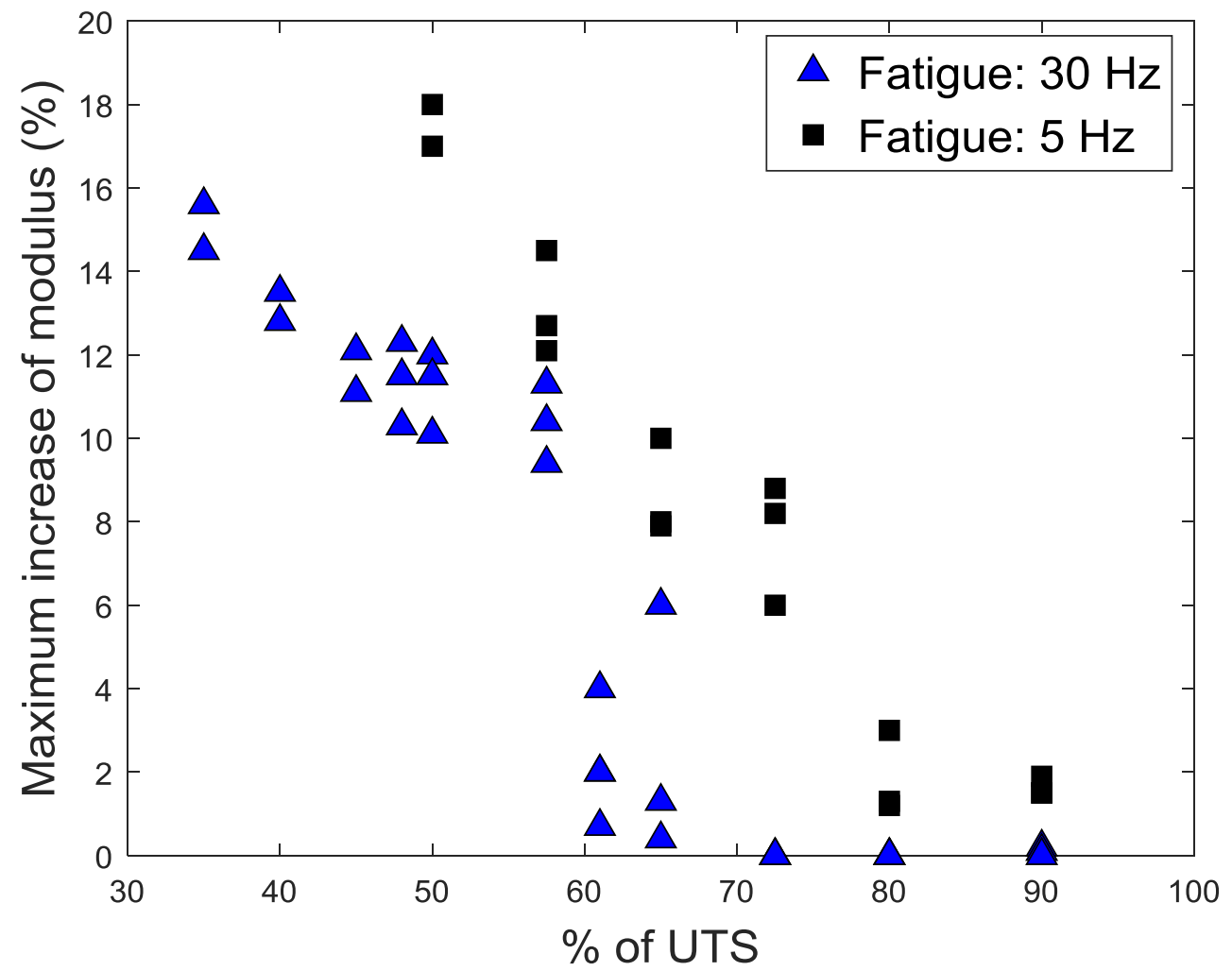

Figure 63: Maximum increase of the dynamic modulus during fatigue test, for a testing frequency of 5 and $30 \mathrm{~Hz}$ respectively. 


\section{CONCLUSIONS}

Results show that the pure unidirectional flax-epoxy composites used in this study is a competitive high-grade composite material, really promising for secondary structural applications. It presents high tensile properties (with a quasi-static rigidity and strength reaching $40 \mathrm{GPa}$ and $400 \mathrm{MPa}$ respectively), a high fatigue resistance (with a maximum fatigue stress of approximately 50 to $55 \%$ of the quasi-static strength for $10^{6}$ cycles), a good stability of its stiffness under cyclic loading (with a dynamic modulus varying only by a factor of 1.14 to 0.95 when compared to its initial stiffness during a large part of the life fraction). It also points out a complex nonlinear behaviour, creep-fatigue interactions and a dynamic stiffening phenomenon. This makes the fatigue understanding and description more complex than for conventional composites.

This study also emphasizes that the increase in the loading frequency from 5 to $30 \mathrm{~Hz}$ influences the creepfatigue damage kinetics, self-heating, and the dynamic stiffening phenomenon. It also induces a decrease in the fatigue strength but only in the middle low cycle fatigue range (between $210^{3}$ and $210^{4}$ cycles) attributed to the high self-heating of the material. Outside this fatigue range, the increase in the loading frequency does not impact significantly the fatigue endurance, meaning that the HCF can be investigated by increasing the loading frequency.

Using a loading frequency of $30 \mathrm{~Hz}$, it is demonstrated for the first time that for this type of composites, in the fibre direction and under tension-tension loading (with a $\mathrm{R}$ ratio of 0.1 ), the maximum stress decreases continuously as a function of the number of cycles. The trend is well predicted using the power law model identified from LCF tests. A maximum stress of approximately $140 \mathrm{MPa}$ is measured for $10^{8}$ cycles. This result clearly shows that this material doesn't reach a fatigue limit and that a decreasing maximum stress as a function of the number of cycles has to be considered, at least up to $10^{8}$ cycles, when designing flax epoxy structures. Despite this feature, results also show an excellent and outstanding behaviour of this type of composite on the HCF range, with a maximum loss in rigidity of $5 \%$, when compared to its initial rigidity, during their own life. The next step will be to supplement this phenomenological study with investigations of damage propagation and fatigue involved mechanisms at the microscale.

\section{Acknowledgements}

The authors would like to acknowledge the funding received from the Bio Based Industries Joint Undertaking under the European Union's Horizon 2020 research and innovation program under grant agreement No 744349 - SSUCHY project and the funding received from the Région Bourgogne-Franche-Comté under grant agreement No 2016Y-06124- D-BCOMP project. The authors also address special thanks to Gerard Michel for his help in machining samples by laser cutting. 


\section{REFERENCES}

[1] Asgarinia S, Viriyasuthee C, Phillips S, Dubé M, Baets J, Van Vuure A, et al. Tension-tension fatigue behaviour of woven flax/epoxy composites

10.1177/0731684415581527. Journal of Reinforced Plastics and Composites. 2015;34(11):857-67.

[2] Bensadoun F, Vallons KAM, Lessard LB, Verpoest I, Van Vuure AW. Fatigue behaviour assessment of flax-epoxy composites. Composites Part A: Applied Science and Manufacturing. 2016;82(Supplement C):253-66.

[3] Bensadoun F, Verpoest I, Van Vuure AW. Residual properties and damage evolution of flax-epoxy composites subjected to fatigue loading. 20th International Conference on Composite Materials2015.

[4] Berges M, Léger R, Placet V, Person V, Corn S, Gabrion X, et al. Influence of moisture uptake on the static, cyclic and dynamic behaviour of unidirectional flax fibre-reinforced epoxy laminates. Composites Part A: Applied Science and Manufacturing. 2016;88:165-77.

[5] de Vasconcellos DS, Touchard F, Chocinski-Arnault L. Tension-tension fatigue behaviour of woven hemp fibre reinforced epoxy composite: A multi-instrumented damage analysis. International Journal of Fatigue. 2014;59(0):159-69.

[6] Dobah Y, Bourchak M, Bezazi A, Belaadi A, Scarpa F. Multi-axial mechanical characterization of jute fiber/polyester composite materials. Composites Part B: Engineering. 2016;90:450-6.

[7] El Sawi I, Fawaz Z, Zitoune R, Bougherara H. An investigation of the damage mechanisms and fatigue life diagrams of flax fiber-reinforced polymer laminates. Journal of Materials Science. 2014;49(5 DO 10.1007/s10853-013-7934-0):2338-46 LA - English.

[8] Fotouh A, Wolodko JD, Lipsett MG. Fatigue of natural fiber thermoplastic composites. Composites Part B: Engineering. 2014;62(0):175-82.

[9] Liang S, Gning PB, Guillaumat L. A comparative study of fatigue behaviour of flax/epoxy and glass/epoxy composites. Composites Science and Technology. 2012;72(5):535-43.

[10] Liang S, Gning P-B, Guillaumat L. Properties evolution of flax/epoxy composites under fatigue loading. International Journal of Fatigue. 2014;63(0):36-45.

[11] Shah DU. Damage in biocomposites: Stiffness evolution of aligned plant fibre composites during monotonic and cyclic fatigue loading. Composites Part A: Applied Science and Manufacturing. 2016;83(Supplement C):160-8.

[12] Shah DU, Schubel PJ, Clifford MJ, Licence P. Fatigue life evaluation of aligned plant fibre composites through S-N curves and constant-life diagrams. Composites Science and Technology. 2013;74(0):139-49.

[13] Sodoke K, Toubal L, Laperrière L. Hygrothermal effects on fatigue behavior of natural fibers composites. 20th International Conference on Composite Materials. Copenhagen, Denmark2015.

[14] Ueki Y, Liholt H, Madsen B. Fatigue behavior of uni-directional flax fibre/epoxy composites. 20th International Conference on Composite Materials. Copenhagen, Denmark2015.

[15] Yuanjian T, Isaac DH. Impact and fatigue behaviour of hemp fibre composites. Composites Science and Technology. 2007;67(15â€“16):3300-7.

[16] Mahboob Z, Bougherara H. Fatigue of flax-epoxy and other plant fibre composites: Critical review and analysis. Composites Part A: Applied Science and Manufacturing. 2018;109:440-62.

[17] Shah DU, Schubel PJ, Clifford MJ. Can flax replace E-glass in structural composites? A small wind turbine blade case study. Composites Part B: Engineering. 2013;52(0):172-81.

[18] Carvelli V, Jain A, Lomov S. Fatigue Limit: A Link to Quasi-Static Damage? Fatigue of Textile and Short Fiber Reinforced Composites: John Wiley \& Sons, Inc.; 2017. p. 87-106.

[19] Vitovec F, Lazan BJ, Tech. MUMIO. Strength, Damping, and Elasticity of Materials Under Increasing Reversed Stress with Reference to Accelerated Fatigue Testing: Defense Technical Information Center; 1955. [20] Liber-Kneć A, Kuźniar P, Kuciel S. Accelerated Fatigue Testing of Biodegradable Composites with Flax Fibers. Journal of Polymers and the Environment. 2015;23(3):400-6.

[21] Barron V, Buggy M, McKenna NH. Frequency effects on the fatigue behaviour on carbon fibre reinforced polymer laminates. Journal of Materials Science. 2001;36(7):1755-61. 
[22] Hertzberg RW, Manson JA, Skibo M. Frequency sensitivity of fatigue processes in polymeric solids. Polym Eng Sci. 1975;15(4):252-60.

[23] Perreux D, Joseph E. The effect of frequency on the fatigue performance of filament-wound pipes under biaxial loading: Experimental results and damage model. Composites Science and Technology.

1997;57(3):353-64.

[24] La Rosa G, Risitano A. Thermographic methodology for rapid determination of the fatigue limit of materials and mechanical components. International Journal of Fatigue. 2000;22(1):65-73.

[25] Montesano J, Fawaz Z, Bougherara H. Use of infrared thermography to investigate the fatigue behavior of a carbon fiber reinforced polymer composite. Composite Structures. 2013;97(Supplement C):76-83.

[26] Gornet L, Wesphal O, Burtin C, Bailleul J-L, Rozycki P, Stainier L. Rapid Determination of the High Cycle Fatigue Limit Curve of Carbon Fiber Epoxy Matrix Composite Laminates by Thermography Methodology: Tests and Finite Element Simulations. Procedia Engineering. 2013;66(Supplement C):697-704. [27] Osti de Moraes DV, Magnabosco R, Bolognesi Donato GH, Prado Bettini SH, Antunes MC. Influence of loading frequency on the fatigue behaviour of coir fibre reinforced PP composite. Polymer Testing. 2015;41(Supplement C):184-90.

[28] Kazymyrovych V. Very high cycle fatigue of engineering materials A literature review. Karlstad: Karlstad University; 2009.

[29] Castellano A, Fraddosio A, Piccioni MD. Quantitative analysis of QSI and LVI damage in GFRP unidirectional composite laminates by a new ultrasonic approach. Composites Part B: Engineering. 2018;151:106-17.

[30] Doan DD, Ramasso E, Placet V, Zhang S, Boubakar L, Zerhouni N. An unsupervised pattern recognition approach for AE data originating from fatigue tests on polymer-composite materials. Mechanical Systems and Signal Processing. 2015;64-65:465-78.

[31] Malpot A, Touchard F, Bergamo S. An investigation of the influence of moisture on fatigue damage mechanisms in a woven glass-fibre-reinforced PA66 composite using acoustic emission and infrared thermography. Composites Part B: Engineering. 2017;130:11-20.

[32] Shin P-S, Kim J-H, Park H-S, Baek Y-M, Kwon D-J, DeVries KL, et al. Evaluation of thermally-aged carbon fiber/epoxy composites using acoustic emission, electrical resistance and thermogram. Composite Structures. 2018;196:21-9.

[33] Unnthorsson R, Runarsson TP, Jonsson MT. Acoustic emission based fatigue failure criterion for CFRP. International Journal of Fatigue. 2008;30(1):11-20.

[34] Assarar M, Scida D, El Mahi A, Poilâne C, Ayad R. Influence of water ageing on mechanical properties and damage events of two reinforced composite materials: Flax-fibres and glass-fibres. Materials \& Design. 2011;32(2):788-95.

[35] De Rosa IM, Santulli C, Sarasini F. Acoustic emission for monitoring the mechanical behaviour of natural fibre composites: A literature review. Composites Part A: Applied Science and Manufacturing. 2009;40(9):1456-69.

[36] Hahn P, Goss T, Karlovsky M, Scheerer M, Pönninger A, Ladstter E. An algorithm for life time prediction of fatigue loaded CFRP-structures derived from the rate of acoustic emission. 4th European Workshop on Structural Health Monitoring2008. p. 1173-82.

[37] Cadu T, Berges M, Sicot O, Person V, Piezel B, Van Schoors L, et al. What are the key parameters to produce a high-grade bio-based composite? Application to flax/epoxy UD laminates produced by

thermocompression. Composites Part B: Engineering. 2018;150:36-46.

[38] Le Gall M, Davies P, Martin N, Baley C. Recommended flax fibre density values for composite property predictions. Industrial Crops and Products. 2018;114:52-8.

[39] Kharrat M, Ramasso E, Placet V, Boubakar ML. A signal processing approach for enhanced Acoustic Emission data analysis in high activity systems: Application to organic matrix composites. Mechanical Systems and Signal Processing. 2016;70-71:1038-55.

[40] Poilâne C, Cherif ZE, Richard F, Vivet A, Ben Doudou B, Chen J. Polymer reinforced by flax fibres as a viscoelastoplastic material. Composite Structures. 2014;112(0):100-12.

[41] Poilâne C, Gehring F, Yang H, Richard F. About Nonlinear Behavior of Unidirectional Plant Fibre Composite. In: Fangueiro R, Rana S, editors. Advances in Natural Fibre Composites: Raw Materials, Processing and Analysis. Cham: Springer International Publishing; 2018. p. 69-79.

[42] Viala R, Placet V, Cogan S. Identification of the anisotropic elastic and damping properties of complex shape composite parts using an inverse method based on finite element model updating and 3D velocity fields 
measurements (FEMU-3DVF): Application to bio-based composite violin soundboards. Composites Part A: Applied Science and Manufacturing. 2018;106:91-103.

[43] Strohrmann K, Hajek M. Bilinear approach to tensile properties of flax composites in finite element analyses. Journal of Materials Science. 2019;54(2):1409-21.

[44] Perremans D, Verpoest I, Dupont-Gillain C, Van Vuure AW. Investigation of the tensile behavior of treated flax fibre bio-composites at ambient humidity. Composites Science and Technology. 2018;159:11926.

[45] Shah DU. Damage in biocomposites: Stiffness evolution of aligned plant fibre composites during monotonic and cyclic fatigue loading. Composites Part A: Applied Science and Manufacturing. 2016;83:1608.

[46] Baley C. Analysis of the flax fibres tensile behaviour and analysis of the tensile stiffness increase. Composites Part A: Applied Science and Manufacturing. 2002;33(7):939-48.

[47] Placet V, Cisse O, Boubakar L. Nonlinear tensile behaviour of elementary hemp fibres. Part I: Investigation of the possible origins using repeated progressive loading with in situ microscopic observations. Composites Part A: Applied Science and Manufacturing. 2014;56:319-27.

[48] Placet V, Cisse O, Boubakar ML. Influence of environmental relative humidity on the tensile and rotational behaviour of hemp fibres. Journal of Materials Science. 2012;47(7 DO - 10.1007/s10853-0116191-3):3435-46 LA - English.

[49] Trivaudey F, Placet V, Guicheret-Retel V, Boubakar L. Nonlinear tensile behaviour of elementary hemp fibres. Part II: Modelling using an anisotropic viscoelastic constitutive law in a material rotating frame. Composites Part A: Applied Science and Manufacturing, In Press. 2014; In Press.

[50] Placet V. Tensile behaviour of natural fibres. Effect of loading rate, temperature and humidity on the "accommodation" phenomena. International Conference on Experimental Mechanics. Poitiers2010.

[51] Yosuke U, Hans L, Bo M. Stiffening effect of fatigue and creep loading in unidirectional flax fibre/epoxy composites. IOP Conference Series: Materials Science and Engineering. 2018;388(1):012018. 